\title{
KONSEP DASAR ALGORITMA DAN PEMROGRAMAN
}

\author{
Oleh: Alchairunnisa.P \\ PMM FITK UINSU \\ annisapanjaitan705@gmail.com
}

\begin{abstract}
ABSTRAK
Algoritma merupakan tahap-tahapan yang diletakkan dalam dokumen dan diurutkan buat memecahkan problem. algoritma software ialah langkah-langkah yang ditulis secara berurutan buat memecahkan problem instalasi personal komputer . pada program sederhana, prosedur pemecahan adalah tahapan pertama yg perlu ditulis sebelum menulis acara. persoalan yang dapat diselesaikan menggunakan program personal komputer artinya persoalan yang berkaitan dengan perbandingan matematis. pada acara aplikasi, prosedur pemecahan sering dilihat menjadi ukuran bagaimana acara akan dieksekusi.
\end{abstract}

Kata Kunci: Algoritma, pemrograman, logika, aktivitas dan komputer.

\section{PENDAHULUAN}

Algoritma berasal dari istilah algoritma dan ritme, yang pertama kali diperkenalkan oleh Abu Ja'far Mohammad Ibn Musa Al Khowarizmi (825M) dalam bukunya Al-Jabr Wa-al Muqobla. Dalam algoritma pemrograman, ini berarti pendekatan khusus yang sesuai dan terdiri dari serangkaian langkah yang terstruktur dan dijalankan dalam skrip pemecahan masalah komputer.

Sikap komputer adalah bahwa itu adalah perangkat "pintar". Ini adalah kekeliruan, karena komputer hanyalah alat yang untuknya orang diberikan serangkaian perintah untuk memecahkan masalah dengan cepat, akurat, dan bahkan konsisten, tanpa kelelahan atau kecanggungan. Serangkaian instruksi pemecahan masalah disebut program. Untuk mengaktifkan program Agar komputer dapat menjalankannya, program harus ditulis dalam bahasa yang dimengerti komputer. Bahasa komputer yang digunakan untuk menulis program dikenal sebagai bahasa pemrograman. Urutan langkah-langkah untuk memecahkan masalah disebut algoritma.

Algoritma berarti solusi. Ketika orang berbicara tentang algoritma dalam pemrograman, itu berarti memecahkan masalah yang perlu diselesaikan dengan komputer. Algoritma harus dibuat secara berurutan sehingga komputer dapat memahami dan menjalankannya. Saat mengembangkan suatu algoritma, diperlukan studi eksperimental, seperti metode apa yang dibutuhkan untuk menyelesaikan masalah yang perlu dipecahkan.

Algoritma ialah aliran atau aliran yang digunakan untuk menghitung atau memecahkan masalah secara sistematis, dan untuk program kerja, algoritma sering dianggap layak untuk membuat program. Algoritma juga merupakan aturan yang dapat digunakan untuk menghitung atau memecahkan masalah, khususnya komputer. Komputer mengawasi proses dan memantau alirannya, dan hasilnya 
dapat dilihat sebagai output. Algoritma program menjelaskan bagaimana melakukan sesuatu dan komputer akan melakukannya sepanjang waktu.

Algoritma pemrograman tidak sama dengan angka. Ada 3 hal yang perlu dipertimbangkan ketika memilih algoritma. 3 pikiran, benar, baik dan baik. Meskipun tingkat teknis proyek adalah algoritma. Dengan kata lain, proyek adalah implementasi dari bahasa proyek. Program dapat didefinisikan oleh bahasa atau struktur informasi sebagai suatu algoritma. Namun, program yang baik memiliki struktur data yang berkembang. Di sisi lain, program data yang buruk dengan algoritma yang baik tidak menghasilkan informasi yang baik.

\section{Kapasitas - Kapasitas Algoritma Pemrograman Dengan Sangat Baik}

1. Metode perhitungan harus seefisien mungkin agar proses perhitungan dapat diselesaikan secepat mungkin. Dengan kata lain, dia tidak menyia-nyiakan sumber dayanya.

2. Metode komputasi yang baik harus mudah diterapkan pada komputer.

3. Program yang baik dapat diakses dengan mudah. Ini adalah proses non-diskriminatif yang dapat dengan mudah dipahami oleh siapa saja. Konsekuensi negatif sulit untuk dikelola.

4. Persyaratan lain dari algoritma berkualitas tinggi. Jika hasilnya salah, ini dapat menghasilkan algoritme perdagangan.

5. Biasanya, semakin baik. Algoritme yang baik biasanya adalah yang permisif dan tidak terbatas pada satu situs. Jika diterima secara universal, maka algoritma dapat memecahkan masalah dan berguna dalam segala hal.

6. Memiliki langkah-langkah yang jelas dan rinci untuk keberhasilan implementasi dan perencanaan. Setiap proses semi-lengkap, lengkap dan tidak lengkap.

7. Algoritma yang baik perlu dikembangkan. Tidak mungkin untuk terus mengembangkan algoritma karena kelihatannya sederhana dan mendapatkan hasil yang lebih tinggi.

\section{Metode Algoritma}

Algoritma adalah proses pengambilan keputusan yang efektif untuk memecahkan masalah. Bahasa yang tepat adalah bahasa kunci. Langkah-langkah yang harus diambil yaitu apakah nilai kebenaran itu benar atau salah. Kesalahan dapat menyebabkan konsekuensi yang salah.

Fase pemecahan masalah adalah proses dari pemecahan masalah ke penciptaan situasi Algoritma. Tahap implementasi adalah proses dimana algoritma mencapai hasil. Hasil dari pertanyaan adalah proses dimana algoritma dikompilasi.

Algoritma adalah seperangkat langkah sederhana untuk memecahkan suatu masalah (KBBI, 1988). Algoritma adalah seperangkat langkah sederhana untuk memecahkan masalah (Rinaldi Munir, 202). Algoritma adalah kumpulan Harus ada seperangkat pedoman dengan langkah-langkah yang jelas dan rinci dalam proses implementasi untuk 
memecahkan masalah atau masalah tertentu sehingga dapat diimplementasikan secara mekanis (Tim Gunadarma, 1988).

Menulis suatu program juga merupakan suatu kedisiplinan ilmu yant diterapkan secara teliti karna program merupakan suatu penerapi dari suatu algoritme. Oleh karna itu dalam menulis suatu program tidak hanya suatu skapivitas saja (Yendri, 2013). Sistem pembelajaran jarak jauh dengan menggabungkan prinsipprinsip yaitu menggunakan teknologi dalam pembelajaran (Chandrawati, 2010).

Ciri-ciri algoritma yang baik:

- Algoritma memiliki logika komputasi langsung atau jalur internal

- Penyelesaian masalah.

- Berproduksi dengan benar dan akurat dalam jangka pendek.

- Cara perhitungan ditulis dengan bahasa yang sederhana dan sistematis serta bersih

- Itu tidak mengungkapkan rahasia.

- Algoritma ditulis dengan cara yang mudah dan sederhana

- Termasuk dalam bahasa proyek.

- Semua tindakan yang diperlukan dijelaskan.

- Semua formalitas dalam algoritma harus diselesaikan setelah beberapa langkah.

Dalam algoritma, langkah pemecahan masalah yang dilakukan berupa pengurutan sekuensial, pemilihanpemilihan, dan pengulangan. Maka ketiga langkah ini membentuk dasar dari algoritma.

a) Pengurutan Sekuensial (perintah)
Struktur organisasi adalah sifat proyek, yaitu setiap lini proyek Urutan top-down dibuat dalam bentuk tertulis.

Contoh dari satu set dua algoritma swapping bilangan bulat adalah:

o Nyatakan A, B, dan C sebagai bilangan bulat

- Tambahkan jumlah A dan B.

- Tambahkan jumlah A kebagian $\mathrm{C}$

○ Tambahkan jumlah B kebagian A

- Tambahkan jumlah C dibagian B

b) perencanaan pemilihan atau manajemen pemilihan

Sebagai pilihan, tidak semua baris program terpenuhi. Lini proyek yang telah selesai adalah satu-satunya jalur yang memenuhi persyaratan. Desain opsi adalah sistem pemrograman yang menjalankan proses pengujian apakah tes atau bagian instruksi harus dihasilkan. Tes status ini dilakukan untuk memilih semua item lainnya.

Contoh soal pilihan adalah menghitung angka yang sama atau berbeda:

- Masukkan nomor sebagai bilangan bulat

- Bagi angka dengan 2 dan tambahkan sisanya ke variabel

○ Jika nilai sisa adalah 0 , ikuti Langkah 4

○ Menampilkan "skor yang sama"

- Jika sisanya tidak sama dengan 0, ikuti Langkah 6

- Tentukan "nomor lain"

c) Rekonstruksi (pengulangan)

Hal besar tentang komputer adalah mereka dapat melakukan hal yang sama tanpa lelah. Badan yang berputar disebut benda yang berputar, dan bagian yang didesain 
ulang dari algoritma disebut benda yang berputar.

Contoh pengerjaan ulang adalah algoritme untuk menampilkan pesan waktu, yaitu:

- Jelaskan cara menyimpan kata-kata

- Beri tahu konverter untuk mempertahankan formatnya

- Sebutkan perbedaan untuk menghitung metode pencarian

- Masukkan pesan dan simpan sebagai perubahan

- Masukkan jumlah pengulangan yang diperlukan dan pertahankan angka $n$

- Atur nilai resistansi ke 0

- Menampilkan pesan di layar

o Tambahkan Penghitung ke 1

- Jika jumlahnya kurang dari n, lakukan langkah 6

- Jika ada nilai yang bertentangan, hentikan proses ini

Jenis - Jenis Algoritma

I. Divide and Conquer

Paradigma untuk membagi masalah utama menjadi permasalahanpermasalahan yang lebih kecil. Pembagian masalah ini dilakukan terus menerus sampai ditemukan bagian masalah kecil yang mudah untuk dipecahkan.

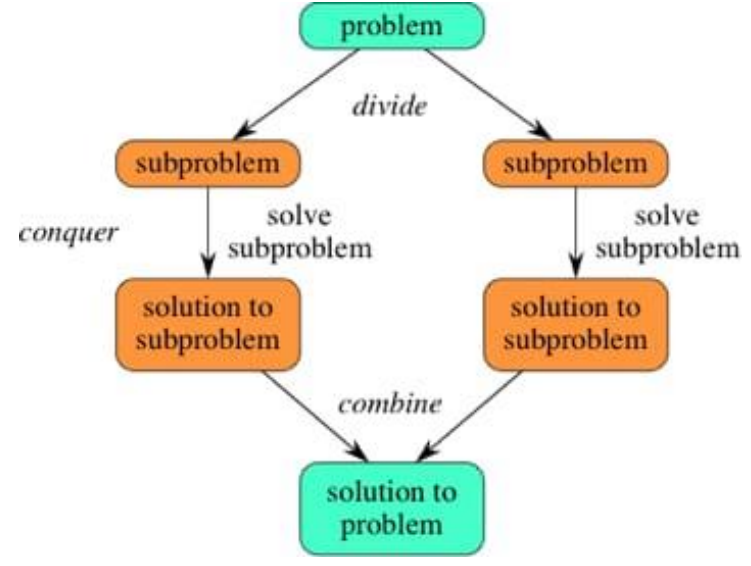

Contoh algoritma divide and conquer yang sederhana

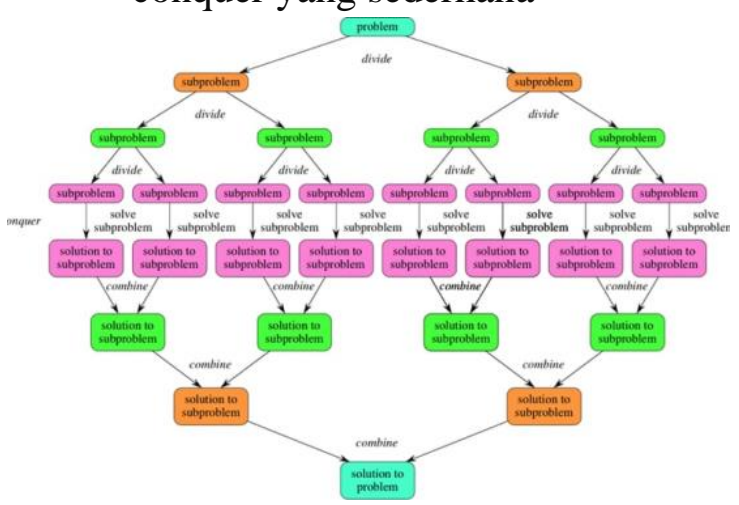

Contoh dari algoritme divide and conquer bentuk kompleks

II. Dynamic programming

Paradigma pemrograman dinamis akan sesuai jika digunakan pada masalah yang mengandung substruktur optimal, dan mengandung beberapa bagian masalah yang tumpang tindih.Paradigma ini terlihat mirip dengan paradigma Divide and Conquer, keduanya mencoba membagi masalah menjadi sub-masalah yang lebih kecil, namun secara intrinsik terdapat perbedaan ciri-ciri persoalan yang diketemui.

III. Metode Serakah

Algoritma serakah menyerupai program serakah, jawaban untuk masalah kecil tidak perlu diketahui di semua tingkatan; Dan gunakan 
opsi "serakah" kali ini untuk selamanya.

IV. Sistem Flowchart

Berikut adalah beberapa simbol yang digunakan untuk menggambar diagram alir.

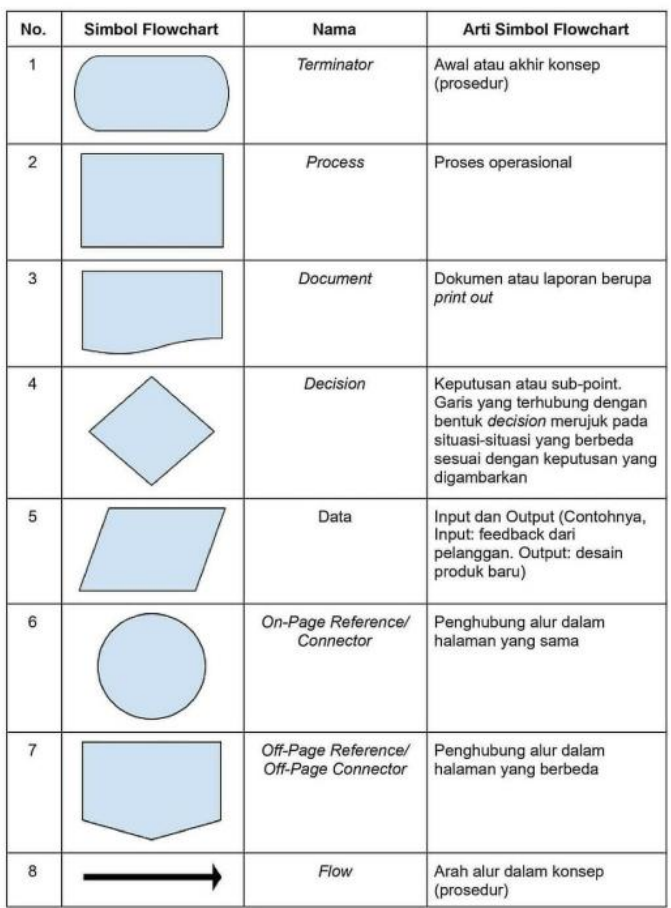

Sistem flowchart adalah diagram alir yang menggambarkan suatu sistem peralatan komputer yang digunakan dalam proses pengolahan data dan hubungan antar peralatan tersebut. Sistem diagram alir tidak digunakan untuk menggambarkan urutan langkah-langkah penyelesaian suatu masalah, tetapi hanya untuk menggambarkan prosedur-prosedur dalam sistem yang sedang dibentuk.

V. Pseudo code (Kode semu)

Pseudo code adalah metode yang cukup efisien untuk menggambarkan suatu algoritma. Pseudo code ditulis menggunakan bahasa yang mudah dimengerti (Bahasa Indonesia dapat digunakan) sehingga penduduk setempat dapat memahami proses yang dijelaskan.

Flowchart kode semu (pseudocode) dibuat dengan maksud untuk menggambarkan level penyelesaian suatu masalah dengan kata-kata (teks). Metode ini mempunyai kelemahan, dimana penyusunan algoritma dengan kode semu sangat dipengaruhi oleh tata bahasa pembuatnya, sehingga kadangkadang sulit dipahami oleh orang lain.

\section{Struktur Dasar Algoritma}

Sifat dari algoritme adalah urutan di mana algoritme dikoreksi dan bagaimana jenis perintah dari algoritme dikonfigurasi. Ada tiga proses utama dalam algoritma: konfigurasi, seleksi, dan desain ulang. Urutan adalah desain yang menggabungkan langkah-langkah algoritme ke dalam bentuk terstruktur.

Choice adalah proses memilih atau memilih hasil yang terbaik. Dengan recreating atau re-creating sifat dari algoritma, proses dapat diulang sampai recreation atau kondisi atau hasil yang sesuai.

- Bagian kepala (Header)

Kepala algoritma adalah bagian yang berisi nama dan deskripsi algoritma, Aturan algoritma yang terkait dengan nama pengetahuan akan dibahas pada bagian selanjutnya. Nama algoritme itu penting, tetapi pikirkan tentang pengetahuan keseluruhan algoritme. Bagian penjelasan dari algoritma memberikan gambaran singkat tentang bagaimana algoritma bekerja. Contoh 
topik algoritma dapat ditemukan di bawah ini.

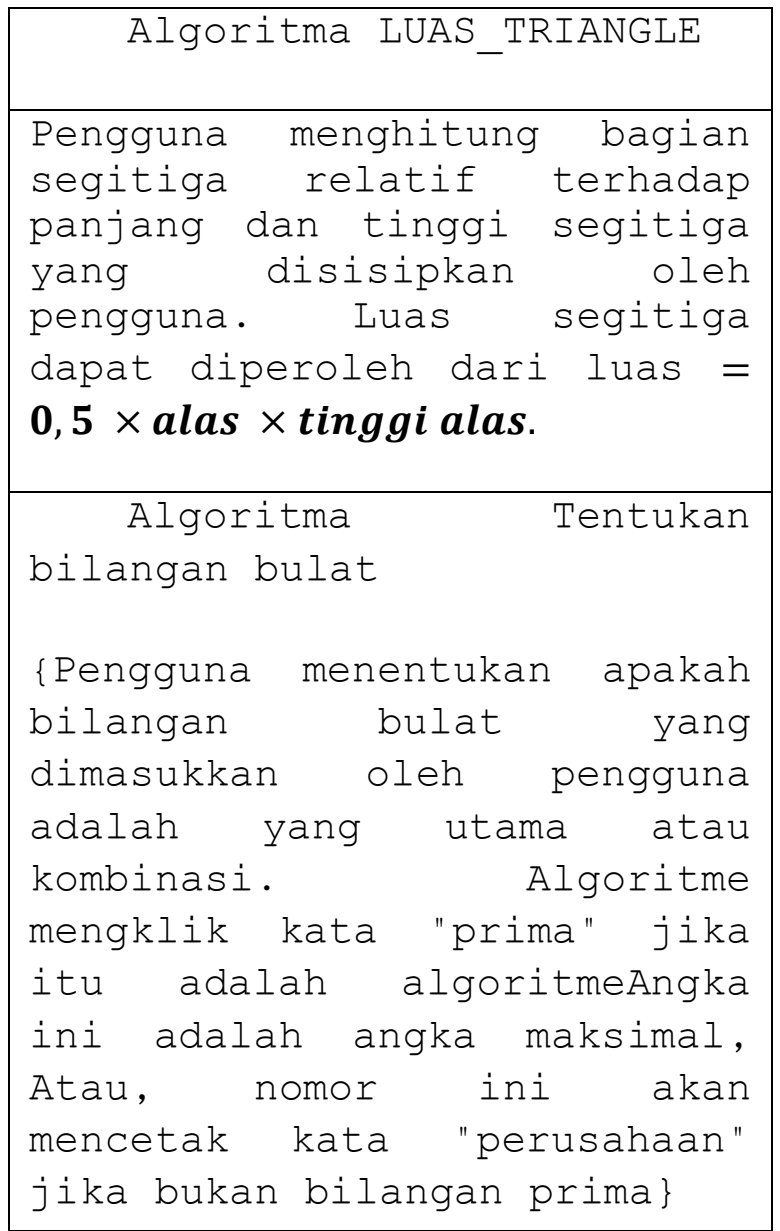

- Bagian pemberitahuan

Bagian notifikasi berisi semua simbol yang digunakan Algoritma. Nama ini bisa berupa nama biasa, nama perubahan (Modifier), nama, nama proses, dan nama fungsi. Contohnya dapat ditemukanRendah.

\begin{tabular}{|l|l|}
\hline \multicolumn{5}{|c|}{ DEKLARASI (Pernyataan) } \\
$02 \mid$ nama pengaturan\} \\
03 | const Npeg $=100$ \\
karyawan\} \\
$04 \mid$ const phi $=3,14$ \{nilai \\
phi\} \\
$05 \mid$ ketik nama\} \\
06 | typeTip: record $\{$ tipe \\
koordinat bidang kartesius \\
$07 \mid<x$,
\end{tabular}

08 | y: bilangan bulat

$09 \mid>$

10 | ganti nama

11 c: char \{karakter yang dibaca\}

12 Q: Titik ftitik dalam koordinat Cartesius\}

13 | ditemukan: boolean \{status hasil penelusuran\}

14 ।

15 | hana IsPrima (input $\mathrm{x}$ : integer) boolean

16 | x Kembali ke kebenaran jika $x$ salah atau salah

Jumlah $x\}$

17 |

18 | Proses Transformasi (input/output a,b:integer)

19 I dan a b Ubah item dalam perubahan

\section{Cara-cara Penulisan Algoritma Pemrograman Dasar}

1. Algoritma Narasi

- Bagian Deskripsi

Memuat langkah-langkah penyelesaian masalah, termasuk beberapa perintah seperti baca data, tampilkan, ulangi, dan sebagainya. Berikut ini adalah contoh sebuah algoritma yang mengikuti struktur tersebut diatas:

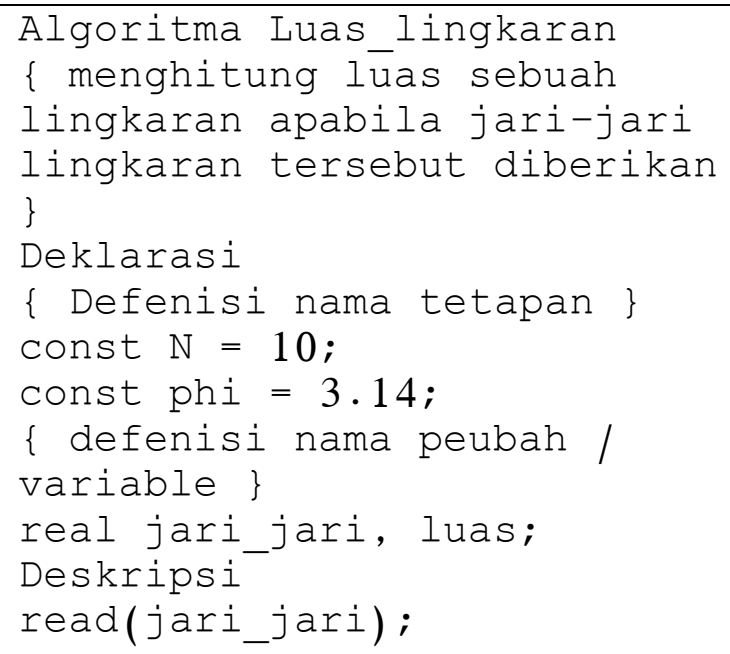




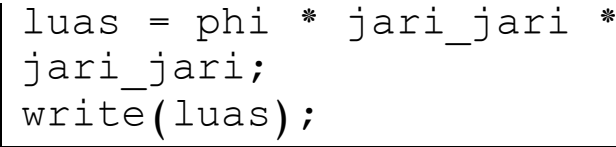

Algoritme memiliki beberapa elemen yang perlu diberi nama atau informasi. Hal-hal Ini adalah: nama algoritmik, nama biasa (s), nama variabel (variabel), namespace, nama proses, dan nama fungsi. Nama harus mematuhi aturan berikut:

1. Termasuk huruf, angka, atau garis bawah

2. Tidak perlu memulai dengan angka

3. Tidak ada perbedaan antara informasi besar dan kecil (tidak peka terhadap situasi)

4. Tidak ada batasan panjangnya

5. Mereka harus sendirian, yaitu, mereka tidak dapat dilihat karena alasan yang sama berbeda.

6. Dia harus membuktikan nilainya Mendaftarkan pemisah ini akan mengikuti salah satu dari 2 metode:

1. Pisahkan kata-kata yang digarisbawahi. Contoh: Luas_Segitiga

2. Pemisahan kata dengan penggunaan kata besar

Contoh nama yang tepat dan tidak pantas:

Nama_4_karyawan \{valid\}

2_area \{Salah untuk pemula dengan angka\}

Bagian dari segitiga digarisbawahi $\left\{\right.$ salah, karena $\left.{ }^{\wedge}\right\}$

Area_Segitiga _ \& _ Panjang $\{$ salah karena $\&$ \} ada.

Hati-hati \{valid

Menurut Donald E. Knuth (1973), algoritma memiliki 5 karakteristik utama:

a. Algoritma Penyelesaian harus diselesaikan setelah menyelesaikan sejumlah langkah.

b. Kejelasan Setiap langkah dari algoritma harus didefinisikan dengan jelas (logis). c. Algoritma plugin tidak dapat dimasukkan, atau satu atau lebih plugin tidak dapat dimasukkan lebih dari satu entri.

d. Harus ada hanya satu output dalam metode perhitungan.

e. Itu akan. Metode perhitungan harus dilakukan dengan benar, yaitu setiap lapisan sangat sederhana untuk mengimplementasikan algoritma yang dapat dilakukan dengan benar dan tepat waktu ketika manusia membuatnya dengan pena dan kertas

\section{Input}

Input melibatkan permintaan informasi yang diperlukan dari pengguna. Misalnya, untuk menghitung luas persegi panjang, Anda memerlukan informasi tentang panjang dan lebar persegi panjang. Artinya, ada dua komponen perhitungan yang menentukan konsistensi potongan, yaitu panjang dan lebar potongan.

\section{Output}

Pencetakan mengacu pada pencetakan informasi yang dihasilkan oleh suatu algoritma. Misalnya, dalam algoritma yang menghitung sepotong, hasil akhir yang Anda inginkan adalah sepotong. Dengan kata lain, algoritma menemukan output yang merupakan daerah segi empat.

\section{Algoritme Flowchart}

Bagan atau diagram yang menggambarkan secara rinci urutan proses atau algoritma dan hubungan diantara satu langkah dengan lengkah lainnya. Contoh: 


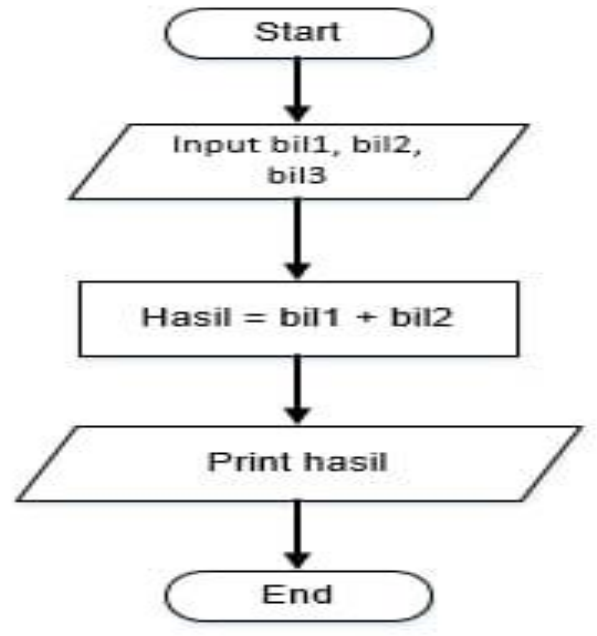

Algoritma Pseudocode

Pseudocode ialah cara penulisan algoritma serupa berdasarkan bahasa pemrograman, tetapi Pseudocode ditulis menggunakan bahasa umum yang mudah dipahami oleh siapa saja. Oleh karena itu, Pseudocode digunakan untuk menggambarkan sifat konsep proyek, terlepas dari bahasa desain yang digunakan. Berikut adalah contoh jenis kode yang ditulis dengan Pseudocode:

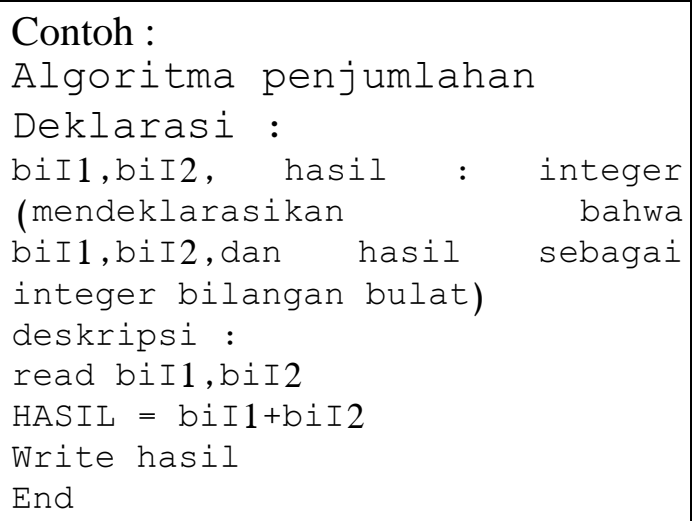

\section{Hasil dan Pembahasan}

Menurut Barakba (2013: 1) Algoritma erat kaitannya dengan istilah algoritma, yang berarti kemampuan manusia untuk berpikir dengan akal tentang suatu Masalah mengungkapkan kebenaran, alasan terbukti dan diterima, evaluasi selalu berhubungan dengan pikiran, orang yang bisa berpikir jernih juga orang menyebutnya sebagai pribadi yang cerdas. Dalam menyelesaikan suatu masalahpun Prinsipnya sangat tepat. Logika sama dengan berpikir dengan akal.

Pertimbangan dalam penerapan algoritma adalah

1) Algoritma haruslah benar, artinya algoritma akan memberikan keluaran yang dikehendaki dari sejumlah Instalasi disediakan. Tidak masalah seberapa bagus algoritmanya, jika memberikan keluaran yang salah, pastilah algoritma tersebut bukanlah algoritma yang baik.

2) Algoritma yang baik harus dapat menghasilkan hasil yang mendekati nilai sebenarnya. Kita perlu tahu bagaimana algoritma bekerja. Ini sangat penting dengan algoritme yang memecahkan masalah yang membutuhkan hasil yang stabil (hasil yang hampir identik).

3) Keakuratan algoritma, seperti akurasi algoritma (mendekati kebenaran), tetapi Lama memperbaiki algoritma, algoritma mana yang digunakan? Karena kunci dari algoritma yang baik adalah jawaban yang benar (mendekati kebenaran) dengan cepat.

Algoritma merupakan suatu alur yang sistemtis untuk memecahkan masalah, Dalam bentuk tayangan dengan streaming foto dan gambar. Algoritma tidak hanya digunakan untuk pemprograman saja, dikehidupan sehari hari pun mengunakan algoritma.

\section{Algoritma untuk menghitung nilai y dari persamaan $y=3 x+8$}

Maka, Algoritmanya :

Mulai

$>$ Tentukan nilai $x$

$>$ Hitung nilai $\mathrm{y}=3 \mathrm{x}+8$

$>$ Cetak nilai $\mathrm{x}$ dan $\mathrm{y}$

$>$ Selesai 
Program ialah perwujudan atau Jalankan algoritma yang ditulis dalam bahasa yang sesuai dapat dilaksanakan oleh komputer. Program ditulis dalam salah satu bahasa pemrograman, dan kegiatan membuat program disebut pemrograman (programmming). Orang yang menulis program disebut pemrogram (programmer). Setiap langkah program disebut pernyataan atau instruksi.

\section{Bahasa Pemrograman}

\begin{tabular}{ccc}
\hline $\begin{array}{c}\text { Bahasa } \\
\text { pemprograman }\end{array}$ & Tipe & Dibuat \\
\hline FORTRAN & Prosedural & 1950 \\
BASIC & Prosedural & 1960 \\
LISP & Fungsional & 1950 \\
Prolog & Deklaratif & 1970 \\
Ada & Prosedural & 1970 \\
SmalTalk & $\begin{array}{c}\text { Berorientasi } \\
\text { Objek }\end{array}$ \\
\multicolumn{3}{c}{1970} \\
Pascal & Prosedural & 1970 \\
C & Prosedural & 1970 \\
C++ & Berorientasi & 1980 \\
\multicolumn{3}{c}{ Objek } \\
\hline
\end{tabular}

Langkah-langkah yang dilakukan untuk menyelesaikan masalah pemrograman dan komputer ialah sebagai berikut:

\section{- Defenisikan Masalah}

Untuk mengetahui apa masalahnya, Anda perlu mengetahui masalahnya tersebut:

a) Persyaratan awal, yaitu proyek yang sudah ada.

b) Kondisi terakhir, yaitu terhapusnya kebutuhan.

c) Data lain yang tersedia.

d) Operator yang tersedia.

e) Persyaratan atau batasan yang harus dipenuhi.

\section{- Bangun Algoritma dan Solusi}

Jika soalnya sulit, maka dibagi menjadi modul. Tahap pengembangan algoritma selalu dimulai dengan level global. Level ini diisi dengan langkah-langkah atau detail tertentu. Metode ini sangat membantu dalam mengembangkan algoritma untuk masalah yang kompleks. Runtuhnya langkah. Masing-masing langkah berikut dibagi menjadi langkahlangkah sederhana. Proses ini akan terus berlanjut hingga setiap langkah selesai.

\section{- Menulis Program}

Algoritma yang dibuat diterjemahkan ke dalam bahasa komputer dalam sebuah proyek. Harap dicatat bahwa memilih algoritma yang salah akan menyebabkan masalah pada program. Program yang baik memiliki tinjauan standar:

a) Teknik untuk memecahkan masalah umum

\section{- Perbandingan atas-bawah}

Cara terbaik untuk memecahkan masalah. Alasannya adalah bahwa masalah yang kompleks dibagi menjadi beberapa subkelompok. Sebuah penelitian dilakukan pada masalah kecil ini. Jika memungkinkan, masalah akan dipecah menjadi bagian-bagian yang lebih kecil dan informasi yang lebih rinci akan ditambahkan setiap hari.

\section{- Teknologi garis bawah}

Prinsip-prinsip sub-teknologi memecahkan masalah yang kompleks Hal ini dilakukan dengan menggabungkan prosedur yang ada Organisasi adalah solusi.

b) jenis proyek

- Kesalahpahaman dan penulisan.

- Lebih sedikit waktu untuk menulis proyek.

- Perangkat lunak berjalan cepat.

- Tip penggunaan memori.

- Praktek pemeliharaan dan perencanaan.

- Pengguna. 
- ambil lima.

- perangkat lunak modular.

c) Informasi yang salah

- Kata (menulis program) salah.

- akan menjadi. Kesimpulan: Konsep, evaluasi, dan dinamika.

\section{KESIMPULAN}

Informasi yang disiapkan dalam instruksi harus ditafsirkan dan diimplementasikan dalam bahasa yang jelas. Bahasa standar adalah bahasa Inggris, tetapi dapat diterjemahkan ke dalam bahasa sehari-hari, seperti bahasa Indonesia. Karena tidak ada aturan dasar untuk menulis algoritma dan komputasi informasi, seseorang dapat membuat aturan penulisan dan metode komputasi informasinya sendiri. Ini dipahami dengan baik karena manuskrip algoritmik dan manuskrip program tidak sama, Selain itu, pseudocode adalah cara untuk menulis algoritma seperti bahasa pemrograman tingkat tinggi. Pseudocode menggunakan bahasa tersebut sebagai bahasa proyek. Kode menipu biasanya menggunakan bahasa yang jauh lebih sederhana dan lebih kompleks daripada algoritma. Pseudocode berisi definisi algoritme perangkat lunak komputer, menggunakan versi yang lebih sederhana dari beberapa pengaturan, tetapi hanya untuk dibaca oleh manusia. Jadi Pseudocode tidak dapat dipahami Di komputer. Agar komputer dapat memahami arti dari pseudocode, terlebih dahulu harus diterjemahkan ke dalam beberapa bahasa pemrograman gramatikal. Menulis perhitungan akhir dan bagan urutan Bagaimana menulis algoritma dengan informasi grafis. Bagan atau diagram yang menunjukkan hubungan antara urutan atau tahapan proyek dan proses serta bahasanya.

\section{DAFTAR BACA}

Budiman. Edy. 2015. Belajar Dasar Algoritma dan Pemograman. Samarinda

Yahfizham, ST., M. Cs. Analisis Waktu Algoritma Quicksort dan Mergesort.

Maulana. Gun Gun. 2017. Pembelajaran dasar Algoritma dan Pemograman Menggunakan El-goritma Berbasis Web. Jurnal Politeknik Mesin. Vol. 06, ISSN : 2549-2888

Suryadi H.S. Agus SUMIN. 1991. Pengantar Algoritma dan Pemograma. Depok.

Allen Marga Retta. Asnurul Iaroqmi. 2017. Pengaruh Penerapan Algoritma Terhadap Pembelajaran

Pemprograman Komputer. Jurnal inovasi pendidikan matematika. Palembang. Vol 2. No 2. 2017.

Sitorus. Lamhot. 2015. Algoritma dan Pemograman. CV ANDI OFFEST

Rajab, Abdul. 2007. Algoritma Pemograman Komputer Berdasarkan Metode Penyelesaian Analitis Terhadap Persoalan Dispatch Ekonom. Teknik Elektro Unand. Vol 1, No 28.

Pengantar Algoritma dan Pemograma. Jurusan Teknik Informatika Fakultas Ilmu Komputer Universitas Almuslim

Hilmi, Novian Dwi Syahrizal \& Rosyid, Harits Ar. 2020. Pengembangan Sistem Kuis Algortima Pemrograman Berbasis Web. Belantika pendidikan, Vol. 3 no. 1, pp 66-74

Ridho, dkk. 2013. Logika dan Algoritma. [Online]. Tersedia: http://entin.lecturer.pens.ac.id/Logika\% 20Algoritma/Buku\%20Logika\%20Algo ritma.pdf. [23 mei 2017].

Yuniansyah. 2020. Algoritma dan Pemrograman Menggunakan Bahasa Pemrograman Jawa (Teori dan 
Aplikasinya). Leuwiliang, Bogor. Lindan Bestari.

Retta, Allen Marga dkk. Bulan Tahun.

Pengaruh penerapan algortima terhadap pembelajaran pemrograman komputer. INDIKTIKA (Jurnal Inovasi Pendidikan Matematika). Vol 2, no 2 ISSN : 2655-2752 